\title{
LA INDUSTRIALIZACION ESPAÑOLA EN EL PRIMER TERCIO DEL SIGLO XX
}

\author{
PABLO MARTIN ACEÑA y FRANCISCO COMIN \\ Universidad de Alcalá de Henares
}

«La industrialización española en el primer tercio del siglo $x x *$ corresponde a la parte dedicada a la economía en el tomo XXXVII (Los comienzos del siglo $X X)$ de la Historia de España de Menéndez Pidal, que dirige el profesor José María Jover '. Como se desprende de su propio título, el trabajo de García Delgado se limita a estudiar un aspecto de la economía española del perío. do 1900-1930: el desarrollo de la industria y la política industrial. La población, el sector agrario o los servicios, aunque elementos cruciales para entender la evolución de la economía española en aquellos años, no se tratan, aunque los dos primeros son estudiados por otro autor en otra sección del mismo volumen. García Delgado aborda su tarea a través de lo que él llama «dos enfoques complementarios»: un estudio global y por etapas del proceso de industrialización, y un análisis de dos sectores -la minería de la hulla y la banca privada.

En buena medida, García Delgado, en su contribución al tomo XXXVII de la Historia de España, nos presenta una impecable síntesis de la historiografía disponible, al tiempo que identifica los principales problemas económicos del periodo y las medidas de política económica más importantes. En el trabajo no existe una tesis central, en el sentido tradicional del término, sobre la industrialización española entre 1900 y 1930, pero, sin embargo, se destacan los tres rasgos básicos que permiten definir claramente ese período: nacionalismo, proteccionismo y corporativismo.

El mérito de García Delgado consiste precisamente en haber detectado estos rasgos (y sus orígenes), en seguirles la pista y, finalmente, en concluir que al final de estas tres décadas se había producido una intensificación y un refuerzo de las posiciones nacionalistas e intervencionistas. Es una lástima que el autor se detenga al final de la Dictadura de Primo de Rivera, ya que de 1930 a 1935 subisten los mismos problemas económicos, aunque agravados,

' J. L. García Delgado, "La industrialización española en el primer tercio del siglo XX\%, en J. M. Jover Zamora (dir.) (1984), Los comienzos del siglo XX. La pobla. ción, la economia, la sociedad (1898-1931), Madrid, Espasa-Calpe, pp. 3-171. 
y la política económica de la II República es similar en muchos de sus aspectos a la de los años anteriores '. Para terminar esta breve introducción, señalemos que el trabajo de García Delgado recoge tanto las aportaciones de numerosos historiadores de la economía como el fruto de sus propias investigaciones ${ }^{3}$, que incorpora y revisa cuando ello se hace preciso.

El autor ha dividido su estudio en seis capítulos: uno introductorio, tres dedicados a las «etapas» de la industrialización y dos a los «sectores específicos".

El primer capítulo está dedicado a la enumeración de las características del viraje nacionalista que se produce a finales del siglo pasado. Ese nacionalismo económico no puede entenderse —e opinión de J. L. García Delgado- sin hacer referencia a dos factores: 1) lo que tiene de reacción frente al capital extranjero (base de la industrialización del xIx); 2) las dificultades por las que atravesaron, en las décadas finales de aquel siglo, los sectores protagonistas de las presiones proteccionistas: triguero, textil, siderúrgico y hullero. El análisis de esos determinantes, de las presiones de las nacientes asociaciones patronales y de las formulaciones doctrinales proteccionistas y nacionalistas es un logro del trabajo comentado. De igual manera lo es la descripción y evaluación de las medidas de protección, fomento e intervención realizadas por el Estado en las tres primeras décadas del siglo xx. No duda en afirmar García Delgado que las notas que caracterizan a esas medidas son su empirismo, su escasa coherencia interna, su ineficacia y sus secuelas distorsionadoras sobre la economía nacional.

Cronológicamente, el período se divide en tres etapas, que corresponden a los años 1900-13 (capítulo II), 1914-22 (capítulo III) y 1923-31 (capítulo IV). Los criterios de demarcación son bélicos o políticos, pero vienen a coincidir con cambios en el ciclo económico. No obstante, esos períodos no son homogéneos económicamente, y aunque los ciclos internos del período 1914-22 estén dibujados en la obra comentada, no ocurre lo mismo con los que se conocen en los otros dos subperíodos. No puede decirse que todo el período de 1900 a 1914 ni el de 1923 a 1931 sean de crecimiento económico. En este aspecto puede sugerirse una primera crítica a la síntesis de García

' Esa es la tesis, al menos, que mantenemos en F. Comín y P. Martín Aceña (1984), «La política monetaria y fiscal durante la Dictadura y la Segunda República», Papeles de Economía Española, núm. 20, pp. 236-261.

${ }^{3}$ De las que queremos destacar algunas de las firmadas individualmente: J. L. Garcí Delgado (1975 a), Origenes y desarrollo del capitalismo en España. Notas criticas, Madrid, Edicusa; J. L. Garcí Delgado (1975 b), «Notas sobre la política fiscal española, 1923.1930\%, en CEVC (ed.), El reparto de la carga fiscal, vol. III, Madrid, Aguilar, pp. 811-865, y J. L. Garcí Delgado (1981), aLa economía española entre 1914 y 1923», en M. TuÑón dE LARA (ed.), «Revolución burguesa, oligarquía y constitucionalismo (1834-1923)», Historia de España, vol. VIII, Barcelona, Labor, pp. 417-458. 
Delgado: para la época existen cifras privadas y oficiales (lo que no quiere decir que totalmente fiables) de las macromagnitudes más imprescindibles para hacer un mínimo análisis de coyuntura. Su utilización, además de singularizar los ciclos internos, hubiese permitido calibrar cuestiones del tipo: ¿cuánto creció la economía española en esas tres décadas?; ¿creció más antes o después de la Primera Guerra Mundial?; ¿ cvarió la estructura sectorial en esos treinta años?

García Delgado señala que los recursos de capital y la renta nacional crecieron a «tasas respetables» entre principios de siglo y la Primera Guerra Mundial; eso es cierto, pero no estaría de más cuantificar la tasa de crecimiento (lo que es factible, por lo menos en el caso de la renta).

Los factores que permitieron el crecimiento económico en los primeros quince años del siglo fueron: 1) la repatriación de capitales; 2) la inversión de capitales extranjeros en sectores estratégicos (en bancos, químicas, eléctricas y servicios urbanos); 3 ) las exportaciones de los sectores dinámicos (hierro, vino, naranja y corcho); 4) la formación de un sistema bancario que se orienta hacia la inversión industrial; 5) la creación de sociedades mercantiles (sobre todo en Asturias, Vizcaya y Barcelona, y en los sectores azucarero, naviero, metalúrgico, textil, minero, químico, eléctrico, seguros y servicios públicos), y 6) la política económica: la estabilización de Villaverde y la política de fomento directo a la producción a partir de 1907.

A pesar de aquel crecimiento, la economía española seguía teniendo, antes de la Primera Guerra Mundial, unos rasgos atrasados: las industrias se localizaban en pocas regiones y escasos sectores; se dependía de las inversiones extranjeras, de la importación de productos básicos para la industria y de la protección exterior, y, por último, existía una dependencia del sector agrario, cuyo atraso paralizaba el crecimiento del sector secundario.

Esos rasgos pondrían de manifiesto, según García Delgado, no el fracaso de la industrialización, sino el carácter desequilibrado, inarmónico y asincrónico de la industrialización española. España en el xIX no habría fracasado en su intento de industrialización, sino que, en opinión de García Delgado —que sigue a Vicens-, se trataba de un proceso de industrialización mediterránea. Pensamos que Nadal tiene razón, en el sentido de que España había perdido el tren de la industrialización del XIx; antes de la Primera Guerra Mundial, la economía española seguía siendo fundamentalmente agraria.

El capítulo que trata de las repercusiones de la Primera Guerra Mundial sobre la economía española es el más acabado, porque es el que más profundamente conoce el autor. Se trata de una síntesis más reducida en espacio, pero más amplia en su perspectiva que otras anteriores. En ella se analizan las tres fases del ciclo bélico: la crisis inicial duró poco, y en 1915 ya se inicia el auge. Las condiciones excepcionales proporcionadas por la neutralidad es- 
pañola permitieron que algunos sectores aumentaran sus beneficios ( $y$ algunos también su producción, pero no mejoraron técnicamente) y que aumentase el número de empresas. Que no era un período corriente queda manifestado en que la balanza comercial tuvo superávit que permitieron exportar capital (nacionalizando activos españoles en el exterior). Asimismo, la desviación de productos al mercado exterior, y la dificultad de importar otros, ocasionaron el problema de subsistencias y acabaron generando una inflación de costes que venía a sumarse a la de beneficios - agravando los costes de la industria española- - Se produjo un proceso de sustitución de importaciones, con lo que florecieron algunos sectores como el químico. Otra muestra de que el período era anormal está constituida porque nadie pidió protección frente al exterior. Quizá eso derivase, en parte, de que las patronales estaban demasiado ocupadas en impedir el triunfo de varios proyectos de reforma tributaria (sobre todo el de Alba de 1916). Otros intentos de política económica fracasaron, como la de subsistencias y la de fomento directo a la industria.

El último período lo dedica García Delgado a la Dictadura de Primo de Rivera; en él estudia las medidas utilizadas para combatir la crisis posbélica, que no son sino la prolongación de las prácticas proteccionistas e intervencionistas que se venían utilizando desde principios del $\mathbf{x x}$; lo único nuevo es el envoltorio corporativista. Se practica la protección frente al exterior, se reinstaura la política de fomento directo iniciada en 1917 y se pone en marcha un mecanismo corporativista que regulará la producción nacional para evitar competencias inútiles que conduzcan a la sobreproducción. Este tipo de política reglamentista es tachado de ineficaz, corrupto, monopólico, inhibidor del progreso técnico, voluntarista y contradictorio. J. L. García Delgado lleva toda la razón, como la llevan Velarde, Palafox y otros autores que le inspiran. Ese intervencionismo del Estado en la Dictadura tiene sus raíces más en el «paternalismo tradicional» que en el nacimiento de un sector público moderno con objetivos racionalizadores. Quizá tenga razón J. L. García Delgado en algunos casos; pero hay intervenciones del Estado en la Dictadura que no son tan anacrónicas, lo que no quiere decir que uno comulgue con ellas. Campsa, el Banco Exterior y la Telefónica, por ejemplo, han durado varios años; lo mismo puede decirse del control de cambios o del Consejo de Ferrocarriles. Por otro lado, las Confederaciones Hidrográficas fueron presentadas por Velarde como una obra innovadora, y -aunque exagerase algo - no le faltaba razón.

Algo parecido podría decirse del presupuesto extraordinario de Calvo Sotelo; no era una cosa tan retrógrada, y permitió financiar obras públicas que no hubiesen surgido en los cauces del ordinario. La política de Calvo Sotelo ha sido juzgada desde distintos ángulos, algunos contrapuestos. García Delgado parece no decidirse por ninguno. Sostiene, basándose en los cálculos de Mel- 
guizo ${ }^{4}$, que el presupuesto del Estado se saldó con déficit, en contra de lo que pregonaba la retórica dictatorial. Como el propio García Delgado sabe, Calvo Sotelo ya reconocía eso, y no creemos que haya nadie que lo niegue. Estamos de acuerdo con él ( $y$ con Melguizo) en que el déficit crónico persistía en su gravedad, pero disentimos en que se incrementase su cuantía (claro que García Delgado debería especificar con respecto a qué años). Quizá nos equivoquemos, pero parece que hay un tono de reproche hacia Calvo Sotelo por aumentar el déficit del Estado (cosa que no hizo). Pero, por otro lado, esa política tuvo efectos favorables - según García Delgado - sobre algunos sectores de la economía, razón por la cual García Delgado la juzgaría favorablemente. Esas son suposiciones nuestras, porque el autor se abstiene de colocarse en una postura o en otra. $\mathrm{Y}$ con relación a la reducción de créditos presupuestarios de 1930, hace algún tiempo García Delgado habló del "Error Argüelles» ${ }^{5}$, lo que suponía implícitamente defender el «acierto de Calvo Sotelo». Notamos que ahora el autor ha variado sus opiniones.

Los dos últimos capítulos se dedican uno al estudio de la minería de la hulla asturiana y el otro al examen de la banca privada en estos primeros treinta años del siglo xx. Se ha de convenir en que el autor conoce bien los problemas de la minería de la hulla en este período, y nos parece que éste es un capítulo muy acabado. En el sector se confirman los rasgos generales que definen toda la economía española: proteccionismo e intervencionismo. Por otra parte, García Delgado pone de relieve los graves problemas de la hulla asturiana, cuyo origen reside no sólo en la falta de demanda, sino también, y básicamente, en una estructura de costes poco competitiva. Altos precios y bajos rendimientos hipotecan al sector y lastran otras partes de la economía española para las que el carbón es un input estratégico. García Delgado presenta una breve descripción de todos estos problemas, así como de la política hullera de la Dictadura.

En cuanto al capítulo sobre la banca privada, nos parece más descriptivo y menos elaborado que el anterior. Resumiendo, digamos que el autor destaca cuatro hechos: primero, la expansión que se registra al comenzar el siglo $\mathrm{xx}$, y que tan magistralmente ha estudiado Pedro Tedde; en segundo lugar, la penetración de la banca extranjera, que, si bien debe recordarse que desde un punto de vista cuantitativo no conviene exagerar, es importante al fomentar un mayor grado de competitividad del sector; en tercer lugar, el fuerte crecimiento bancario durante los años de la guerra europea y en la década siguiente, que se manifiesta tanto en el número de entidades bancarias que

4 A. Melguizo (1979), «El presupuesto de Calvo Sotelon, Cuadernos Económicos de $I C E$, núm. $10, \mathrm{pp} .301 .462$.

'J. L. García Delgado (1980), «La política económica española de 1930: “el error Argüelles"». Papeles de Economia Española, núm. 1, pp. 43-37. 
surgen como en la expansión del volumen de activos y pasivos, y, finalmente, la consolidación de la banca mixta, cuyo resultado es una mayor interrelación entre industria y entidades de crédito.

Antes de concluir, permítasenos añadir tres comentarios críticos. El primero es reiterar algo que ya hemos señalado: la obra debería haberse prolongado hasta 1935, y con ello habríamos logrado una visión de conjunto de un período (1900-1935) que para los autores de esta «Nota» está caracterizado por la continuidad de las políticas económicas y del proceso de modernización. Tampoco se le escapa a nadie que, para ser un estudio de la industrialización en el primer tercio del siglo xx, el trabajo queda cojo: sólo se examinan en detalle dos sectores, y aunque otros de la misma importancia son mencionados en los capítulos II, III y IV, su tratamiento no es lo completo que cabe desear. J. L. García Delgado coincide, sin duda, con estas dos apreciaciones críticas, pero habrá tenido que plegarse a las necesidades de edición de una obra colectiva. Y tercero, falta un capítulo final de conclusiones, en el que el autor hubiese podido recoger los principales argumentos de su investigación y los hechos más destacados del período. Peccata minuta: opinamos que García Delgado recurre en exceso a las citas, cortas y largas, sin duda fruto de su inveterada inclinación a respetar la opinión y prosa de los autores y obras que apoyan su argumentación. Empero, esta técnica hace difícil a veces saber cuál es su interpretación de los hechos y si coincide o discrepa de la del autor que cita. De todos modos, como García Delgado cita con rigor, la contrapartida positiva es que gracias a él llegamos a conocer textos, opiniones, expresiones y frases felices que de otro modo nos pasarían inadvertidos.

En resumidas cuentas, pese a estas críticas de detalle, quizá debidas más a nuestra miopía de especialistas que a discrepancias objetivas con la obra comentada, la contribución de García Delgado cumple sobradamente con el empeño de ofrecer una síntesis general de la industrialización española en las tres primeras décadas del siglo $\mathrm{xx}$, como era de esperar de uno de los mejores especialistas de la economía del período. Eso constituye un avance, pues habiendo buenas obras que presentan aisladamente la economía de antes de 1914, de después de esa fecha, de la Primera Guerra Mundial y de la Dictadura, existía el vacío de un compendio de todo el período realizado con vocación de identidad y continuidad. No hay que insistir en que la facilidad del autor para esquematizar y exponer con sencillez los problemas convierte esta obra en un excelente manual para los estudiantes de Historia Económica. 